\title{
artigos
}

\section{SISTEMA ÚNICO DE SAÚDE: AVALIAÇÃO E PERSPECTIVAS*}

Juan S. Yazlle Rocha**

Resumo: $O$ autor analisa os problemas atuais com que se debate o SUS. Resgata, da história recente, o processo que levou sua inclusão no texto da Constituição de 1988. Analisa, a partir de então, as dificuldades na sua implantação. Seus avanços e recuos. Conclui elencando os desafios do presente, tanto na esfera da prática política quanto na da construção teórica.

\section{ANTECEDENTES:}

O campo hoje conhecido como Saúde Coletiva continha, até meados dos anos 80 , duas correntes principais: uma primeira representada pela Saúde Pública, oposta medicina curativa individual, voltada a problemas da comunidade que exigem uma resposta coletiva e, a Medicina Preventiva, projeto americano de reforma da educação médica, que defendia a medicina integral e a prevenção das doenças pela intervenção na sua história natural. $O$ final dos anos 60 estaria marcado pela divisão deste campo em duas vertentes antagônicas: a primeira, que chamarei de Não-Saúde Pública, originou-se a partir da evolução das duas correntes pré existentes e tinha por objetivo a racionalização e reforma da estrutura da saúde no pais; desenvolveu a organização da ações de saúde em Programas

\footnotetext{
•Baseado em exposição no IV Congresso Paulista de Saúde Pública em São Paulo, em 1993

- Secretário Municipal de Saúde de Ribeirāo Preto-SP Prof. Titular de Medicina Social da FMRP-USP
} 
enfatizando as idéias de cobertura da população e normatização das atividades em nome da eficácia e eficiência. A segunda vertente, a Medicina Social, inspirada no movimento socialista, defendia a transformação do Estado e da Sociedade capitalista apontados como responsáveis pela situação de miséria e penúria da população; somente assim seria possivel desenvolver políticas sociais e serviços de saúde adequados; era um movimento de resistência aos governos militares que defendia a redemocratização do pais.

De 1979 a 1981 ocorre a grave crise financeira da Previdência Social que abre espaço para o processo de reorganização da assistência médica previdenciária a partir do interior das Instituições públicas. Impulsionado pelo conteúdo das propostas do PLANO DO CONASP, o Movimento Sanitário Brasileiro supera o confronto entre as vertentes racionalizadora e transformadora ao construir a sintese representada pelo campo e doutrina da Saúde Coletiva (ver: Min. Saúde VIII Conferência Nacional de Saúde, Relatório Final, 1986). O consenso conseguido naquele momento daria origem, na Constituição de 1988, ao Sistema Único de Saúde. Desta forma se conseguiu introduzir mudanças no papel do Estado e se alterou profundamente $o$ arcabouço jurídico-institucional do sistema público de saúde, criando espaços para a participação da sociedade, novas relações entre as diferentes esferas de governo, novos papéis entre os atores do setor.

\section{SISTEMA ÚNICO DE SAÚDE: AVANÇOS E RECUOS}

O sucesso do avanço conseguido não pode ocultar as divergências, os sucessos e insucessos das correntes racionalizadoras da saúde e transformadora da sociedade no interior do Movimento Sanitário seis anos após a promulgação da Constituição-Cidadã de 1988. O Movimento pela transformação da sociedade 
conseguiu imprimir traços avançados no Sistema Único de Saúde, caracterizando a saúde como direito de todos e dever do Estado: ganhou o controle social em espaços institucionais nos municipios, estados e União. Não pode, todavia descentralizar e democratizar o poder face vaga neo-liberal que propugna, ainda agora, o descomprometimento do Estado com o direito saúde. A corrente racionalizadora pode contar com avanços como a integração, regionalização e hierarquização do sistema; não pode, todavia realizar seu projeto de reorganização das práticas.

A grave crise que acomete o setor público da saúde no país é, antes de tudo, o resultado lógico da falta de vontade política daqueles que, derrotados na reforma da constituição, ganharam o poder central e dedicaram-se a inviabilizar a implantação do SUS. Esta política de oposição ao SUS, comandada pelos setores mercantilistas da saúde encontrou sustentação dentro da política neo-liberal do governo Collor e se traduziu no protelamento da extinção do INAMPS, na centralização das decisões, no solapamento das bases financeiras do SUS com a desregulamentação do FINSOCIAL e nos vetos lei Orgânica da Saúde. Somente com o segundo Ministro da Saúde do periodo Collor e, principalmente após a IX Conferência Nacional de Saúde e o trauma do impeachment, é que iria mudar o rumo seguido pelo Ministério da Saúde: em 1993, após a significativa publicação de um documento intitulado A CORAGEM DE CUMPRIR E FAZER CUMPRIR A LEI, O terceiro Ministro da Saúde do período Collor-Itamar sentaria as bases para a descentralização da saúde, 5 anos após a promulgação da Constituição, propondo uma transição gradualista de gestão: incipiente, parcial, semiplena e plena. A importância e alcance da questão da centralização, bem como do despreparo para a sua efetivação nesses 5 anos, pode ser aquilatada no próprio documento: são pressupostos da descentralização: redistribuição do poder, estabelecendo novas 
relações entre as esferas de governo; as dimensões políticas sociais e culturais do processo; a existência e funcionamento regular dos Conselhos de Saúde paritários e deliberativos; a responsabilidade pelo financiamento da saúde que deve ser compartilhada pelas 3 esferas de governo (vide a Norma Operacional Básica 01/93, portaria $n^{\circ} 454$ MinSaúde 20/05/93). Além dos conselhos já existentes, foram criadas as Comissões Intergestores $\mathrm{Bi}$ e Tripartites, reunindo representantes dos respectivos niveis de governo. Estabelecidas as bases legais para a descentralização do sistema de saúde os adversários puderam encontrar vários pontos que atrazaram e inviabilizaram o aprofundamento do SUS, velando a causa real: a falta de vontade política de implementar o modelo de saúde que, embora atenda muito melhor população, contraria interesses históricos no setor. Argumentou-se com dificuldade de regulamentar o artigo 35 da LOS que estabelece os critérios populacionais e epidemiológicos para efetivação dos repasses financeiros; com isto se mantém o pagamento por produção, fator de distorção que renumera melhor quem possui maior capacidade instalada de serviços; gastariam-se meses para discutir minutas de convênio entre a união e os municipios para "legalizar" repasses fundo a fundo, previstos em lei ainda não cumprida. Reduziu-se 0 investimento financeiro federal na saúde de 80 dólares/hab/ano em 1989 para menos de 40 dólares em 1993 de forma que a falta de recursos financeiros desestimulou os municipios a assumir a gestão local do SUS; foi diminuido o repasse de recursos do orçamento da seguridade social para o Ministério da Saúde, ao arrepio da Lei; mais tarde, o pagamento pelas empresas da dívida do Finsocisal foi parcelado em 80 meses. Esta política explica tamanho insucesso da municipalização, quase 6 anos após a criação do SUS. Segundo dados do Ministério da Saúde, dos quase 5000 municipios brasileiros, em 20/05/94 apenas 1667 (de 19 Estados diferentes) haviam pedido enquadramento de Gestão Municipal: 1092 incipientes, 541 parciais, 33 semi- plenos e 01 pleno; se 
considerarmos que a gestão incipiente é a continuidade do Convênio SUDS na era do SUS, temos que somente 575 municipios avançaram na municipalização, ou pouco mais de $10 \%$ do total. No Estado de São Paulo a crise financeira foi mais grave porque a Secretaria de Estado da Saúde optou por pagar integralmente aos prestadores privados cortando até $70 \%$ do valor faturado pelos municipios; nesta situação, o SUS transformou-se em presente de grego: repassava os encargos sem os recursos necessários. Com a aceleração da inflação, o pagamento, atrasado em 60 dias, representou um corte de quase $50 \%$ do valor faturado. Não tendo sido concretizada a transferência da gestão do sistema, o poder local não se realizou como deveria. A instalação das Comissões Bipartites Estaduais e Regionais significou a instauração de novos foros de análises da crise da saúde, com pouca interferência no controle da aplicação dos recursos e na definição das políticas. $O$ mesmo podemos dizer da atuação dos Conselhos os quais, na maior parte das vezes, são tutelados e transformados em dóceis instrumentos das administrações. Esta conclusão é preocupante já que, em muitos Estados, a saúde é o setor mais mobilizado e politizado onde ocorre mais intensamente a participação dos diferentes segmentos sociais. Não poderia ser de outra forma em vista da fraca tradição de cidadania que dificulta a consolidação de um verdadeiro poder local.

Esta politica prosseguiu antes e durante a implantação do Real; para a criação do Fundo Social de Emergência forma feitos grandes cortes nos orçamentos federais da saúde e da educação. hoje responsáveis pela crise financeira do setor. Posteriormente, a conversão da tabela de procedimentos para o real sofre um achatamento extra, ao deixar de aplicar-se a regra geral da conversão dos valores pela média dos últimos 4 meses. Realiza-se o desejo dos economistas neoliberais: de um lado promover cortes que garantam o ajuste fiscal a fim de garantir o Plano de estabilização da moeda; de outro cristalizar a menor 
participação do Estado no financiamento do sistema público de saúde. O mais grave de tudo é que tensionando as relações entre municipios-estados e união criou-se um clima adverso para o estabelecimento e desenvolvimento de parcerias entre os diversos níveis de governo, indispensável ao adequado desenvolvimento do sistema.

Todavia é preciso reconhecer que este processo de luta em defesa do SUS teve seus "heróis" que souberam manter a chama acesa, fazer avanços e conquistar posições; eles estão no Ministério da Saúde, nos Estados e nos municipios: o principal resultado do seu trabalho foi ter evitado o colapso total do SUS o que abriria espaço para a privatização do sistema de saúde. Onde foi possivel alcançar a municipalização logo ficou evidente que o controle legal com participação da comunidade é capaz de melhorar a assistência médica população e desenvolver ações de controle de epidemias e endemias reduzindo o desperdício dos recursos minguados e aplicando com maior adequação e criatividade os recursos, apesar das condições adversas no plano federal.

\section{QUESTÕES DO PRESENTE:}

Devemos ter claro que além da vontade politica para sustentar o desenvolvimento do Sistema Único de Saúde é essencial a elaboração e solução de várias questões, muitas das quais não previstas, e outras que, embora sabidas. carecem de soluções provadas. Uma questão central é a mudança do modelo assistencial hoje centrado na medicina curativa com elevado consumo de atos e serviços médicos e a conseqüente fragmentação da assistência em milhares de atos, muitos desnecessários e até nocivos saúde, que não impactam no nivel de saúde ( nâo é por outra razão que neste periodo temos a eclosão de surtos e 
epidemias). Sem capacidade de determinar os investimentos e as ações da saúde, não pode ser modificado o modelo assistencial. Integrar as ações de saúde e ordená-las dentro de uma perspectiva médica e epidemiológica, e não de consumo (mercantilista) de serviços é ainda um grande desafio.

Tenho observado também, e creio que deva ser considerado que se tivesse ocorrido a efetiva transferência de poder do centro aos municipios teriamos uma crise de crescimento do SUS durante o tempo de latência para formar a mãode-obra qualificada necessária para realizar a tarefa gerencial local em quase 5000 municipios; como formar rapidamente em torno de 50.000 sanitaristas, epidemiólogos, administradores-planejadores, etc? Em muitos lugares a falta deste profissionais qualificados representa a impossibilidade de realizar o poder local que a Reforma Sanitária Brasileira requerer.

Outro assunto que merece elaboração é a questão da gestão local diante da existência de serviços regionais que atendem a vários municípios. Portaria ministerial determinou que a contratação dos serviços destes estabelecimentos deve passar pelo nível regional, não podendo ser decidido pelo gestor do municipio sede. Isto implica em um poder regional, inexistente hoje e que deve ser construido a partir de estudos baseados em análise concreta das condições e características dominantes na região específica.

Finalmente outro ponto que proponho considerar é a construção dos Sistemas Estaduais de Saúde a partir de parcerias Estado-Municípios. Os Estados continuam responsáveis pelos serviços públicos de referência regional; se eles funcionarem mal, sofrerão os municipios que deverão compensar as deficiências encontradas. Ainda vivemos numa realidade dominada pelo clientelismo politico onde prefeitos do mesmo partido ou aliados do governador do estado recebem tudo 
e os adversários são tratados quase como inimigos, a conseqüência disto é a conhecida fisiologia ou submissão dos carentes diante daqueles que administram recursos públicos. A verdadeira parceria só aparecerá depois de consagrar-se o repasse fundo a fundo dos recursos financeiros, quebrando a atual dependência das administrações municipais.

É necessário reconhecer que nestas 3 últimas décadas a Saúde se transformou sem, todavia, acabar seu processo de mudanças. Com isto nós temos que novos objetos e novas questões, teóricas e práticas, estão postas para elaboração e desenvolvimento exigindo estudo, debate, trabalho e implantação. Junto queda do socialismo real e a onda neo-liberal, temos o questionamento da eficácia administrativa do setor público e da capacidade financeira de implementar um modelo universal e equânime. Os adversários do SUS pretendem que está demonstrada a sua inviabilidade, ainda que não tivesse tido oportunidade de ser integralmente implantado. Os que não puderam impedir os avanços inscritos na Constituição e conseguiram impedir a sua implementação agora se reorganizam para planejar o retrocesso. Cabe a nós, integrantes do Movimento Sanitário demonstrar, na prática, a superioridade do Sistema único de Saúde para responder $s$ necessidades da sociedade brasileira. 